\title{
Numerical Prediction on the Mechanical Behaviour of Laser Peened Bulk Metallic Glass
}

\author{
J. Fu, H.G. Shi, C. Zheng, R. Liu, Z. Ji* \\ Key Laboratory for Liquid-Solid Structural Evolution and Processing of Materials (MOE), School of Materials Science and \\ Engineering, Shandong University \\ PR China \\ *Corresponding author
}

\begin{abstract}
Laser peening is an innovative surface treatment technique similar to shot peening, but it can introduce deeper compressive residual stress layers to materials for improving their fatigue life and plasticity. In this paper, a three dimensional finite element model has been developed to numerically simulate the laser peening and subsequent three-point bending of a bulk metallic glass $\left(\mathrm{Zr}_{41.2} \mathrm{Ti}_{13.8} \mathrm{Cu}_{12.5} \mathrm{Ni}_{10} \mathrm{Be}_{22.5}\right)$ beam by using Abaqus software. The constitutive relation used here is based on the free volume theory. Compared the laser peened beam with un-peened beam, the simulated results shown that the improvement in mechanical performance is attributed to the induced compressive residual stress and the free volume increase in the peened area. The yield strain and the yield strength of laser peened BMG are also increased. This research presents how laser peening improves the strength and plasticity of brittle and strainsoftening bulk metallic glasses.
\end{abstract}

Keywords-finite element analysis; laser peening; bulk metallic glass; mechanical performance; free volume

\section{INTRODUCTION}

Bulk metallic glasses (BMGs) have attracted great attentions due to their high strength, low Young's modulus and unique physical properties. The BMGs have a different deformation mechanism and different yield behavior from traditional crystalline materials because of their homogeneous structures without dislocations. However, most BMGs are brittle and strain-softening, they exhibit zero or limited plastic strain during deformation at room temperature, which restricts their practical applications as structure materials [1, 2]. Therefore, improving the plasticity of BMG has become a very important topic. For example, Greer et al [3] reported that hard shots in an air blast repeatedly bombard the surface of BMG resulting in a high level of compressive residual stress and a low level of tensile residual stress. This residual stress distribution will enhance the plasticity of metallic glass. As a highly controllable and precise technique, laser peening can not only introduce residual compressive stresses but also result in free volume concentration to the BMGs, both of which are beneficial for enhancing their plasticity. Compared with shot peening, laser peening can induce greater depths of residual stress into material surfaces using high-power, short and intense laser pulses. As the result, laser peening can obtain better surface quality and greater plasticity. It has been proposed as a competitive technology for improving fatigue life and strength of the material through surface modification in the future $[4,5]$.
In this work, a constitutive equation is established for the special deformation behaviors of BMG such as strain softening. The equation is based on the free volume theory, and is hydrostatic pressure sensitive and strain rate dependent. Meanwhile, taking account of the mechanical model of laser peening, a three dimensional finite element model of a BMG beam is employed to investigate the residual stress distribution and the free volume distribution after laser peening. Compared the bending processes of laser peened and un-peened BMG beam, it is proved that the plasticity improvement of laser peened materials is attributed to the compressive residual stresses and free volume increase.

\section{SiMULATION STRATEGY}

\section{A. Finite Element Model}

A three dimensional finite element model has been developed to simulate the laser peening process and the subsequent three point bending process by using Abaqus soft. The schematic of this finite element model is shown in Figure. 1. This simulation has two processes: laser peening and the following three point bending. During laser peening, laser shock pressure is applied to the central area of top and bottom surface of the beam with size $10 \times 2 \times 1 \mathrm{~mm}(\mathrm{x} \times \mathrm{y} \times \mathrm{z})$, the material of the beam is $\mathrm{Zr}_{41.2} \mathrm{Ti}_{13.8} \mathrm{Cu}_{12.5} \mathrm{Ni}_{10} \mathrm{Be}_{22.5}$. The both end surfaces of the beam are fixed. The diameter of laser spot is $1 \mathrm{~mm}$. When the pressure is unloaded, the beam reaches to steady after a period of springback. Then, the beam is being bent into the die when the punch moves down. The die and the punch are considered as rigid, they do not require meshing and define material properties. Table 1 shows the mechanical properties of the BMG. In this process, the downward displacement of the punch is $2 \mathrm{~mm}$ and the total time is 0.07 ms.

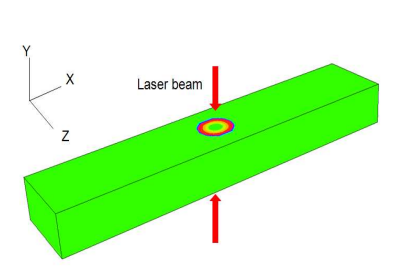

(a)

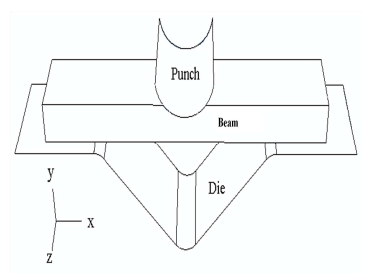

(b)
FIGURE I. THE FINITE ELEMENT MODEL (A) LASER PEENING MODEL (B) BENDING MODEL. 
TABLE I. MECHANICAL PROPERTIES OF ZR41.2TI13.8CU12.5NI10BE22.5.

\begin{tabular}{|c|c|}
\hline Properties & Value \\
\hline Density, $\rho\left(\mathrm{g} / \mathrm{cm}^{3}\right)$ & 6.125 \\
\hline Poisson ratio, $v$ & 0.36 \\
\hline Elastic modulus, $E(\mathrm{Gpa})$ & 96.0 \\
\hline Yield strength, $\sigma_{s}(\mathrm{Gpa})$ & 1.8 \\
\hline Internal friction coefficient, $\mu$ & 0.07 \\
\hline Critical volume, $v^{*}\left(\mathrm{~mm}^{3}\right)$ & $2.34 \times 10^{-20}$ \\
\hline
\end{tabular}

\section{B. Constitutive Model and Laser Shock Pressure}

Unlike crystalline materials, the plastic deformation of BMG depends on free volume theory and has a characteristic of strain softening. The free volume model, since proposed by Cohen and Turnbull and developed by Cohen and Spaepen [6, 7], has been widely used to explain various properties of metallic glasses. In this study, Gao's model [8] is applied to describe the mechanical behavior of laser peening. It is a multi-axial generalization of the free-volume model. The driving force of the free volume evolution can decrease the viscosity. As a consequence, the constitutive relation shows a softening behavior, which further leads to the localized deformation. Based on the effect of hydrostatic-pressure sensitivity, the free volume evolution and the flow equation are generalized to multi-axial stress states:

$$
\begin{gathered}
\dot{\varepsilon}_{i j}^{p}=\exp \left(-\frac{1}{v_{f}}\right) \sinh \left(\frac{\sigma_{e, n}+\Delta \sigma_{e}}{\sigma_{0}}\right) \frac{S_{i j}}{\sigma_{e}} \\
\dot{v}_{f}=\frac{1}{\alpha} \exp \left(-\frac{1}{v_{f}}\right)\left\{\frac{3(1-v)}{E}\left(\frac{\sigma_{0}}{\beta v_{f}}\right)\left[\cosh \left(\frac{\sigma_{e, n}+\Delta \sigma_{e}}{\sigma_{0}}\right)-1\right]-\frac{1}{n_{D}}\right\}
\end{gathered}
$$

Where, $v$ : frequency of atomic vibration normalized free volume

$v^{*}$ : critical volume

$\Omega$ : atomic volume

$\beta$ : constitutive parameter, $\beta=v^{*} / \Omega$

$k_{B}$ : Boltzmann constant

$T$ :absolute temperature

$\sigma_{0}$ : reference stress, $\sigma_{0}=2 k_{B} T / \Omega$

$S_{i j}$ : deviatoric stress tensor, $S_{i j}=\sigma_{i j}-\sigma_{k k} \delta_{i j} / 3$

$\sigma_{e}$ : von-Mises stress,$\sigma_{e}=\left(1.5 S_{i j} S_{i j}\right)^{0.5}$

A internal friction can be introduced to this model [9]. The increments of the effective stress $\Delta \sigma_{e}$ can be described by introducing internal friction coefficient $\mu$ and summation of the normal stresses $\sigma_{k k}$.

The laser pulse pressure is of temporal and spatial distribution model. The laser pressure varies simultaneously with time history of the laser pulse and radial distance from the center of the laser spot. The pressure time history is assumed to be known in advance because the simulation procedure does not explicitly model the physical process [10]. The spatial distribution of laser shock pressure follows a Gaussian distribution. Maximum pressure is located at the center of the laser spot and decreases with increasing radial distance from the center. It can be represented by the following equation [11]:

$$
P(r, t)=P(t) \exp \left(-\frac{r^{2}}{2 R^{2}}\right)
$$

where $R$ is the radius of the spot and $\mathrm{r}$ is the radial distance from the center of the spot. In this study, the value of $R$ is $0.5 \mathrm{~mm}$, and $r<=0.5 \mathrm{~mm}$.

\section{RESULTS AND DISCUSSION}

\section{A. Laser Peening Results}

Figure. 2(a) shows the residual stress distribution of the laser shocked beam before bending simulation. The residual stress distribution has been investigated quantitatively in depth direction and the result is shown in Figure. 2(b). The compressive residual stress is introduced to the top and bottom surfaces and the tensile residual stress is introduced to the interior of the beam. Along the thickness direction (y), compressive residual stress is gradually transitioning to the internal tensile residual stress, and the maximum value of compressive residual stress is to $430.2 \mathrm{MPa}$. The residual stress induced by laser peening has some leverage over the following bending process.

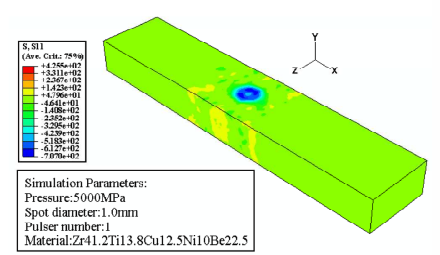

(a)

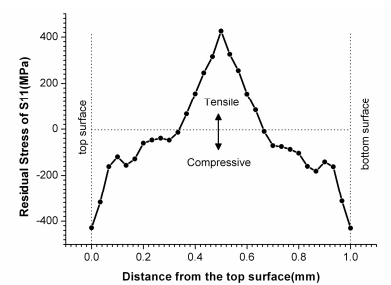

(b)
FIGURE II. RESIDUAL STRESS DISTRIBUTION (A) BEFORE BENDING (B) IN DEPTH.

\section{B. Bending Results}

Figure. 3(a) shows the contour of equivalent stress distribution after bending. The top surface which is next to the punch is the most intense deformation zone and is introduced to compressive stress. The maximum stress is $1512 \mathrm{MPa}$. The bottom surface is introduced to tensile stress and the maximum stress is $1154 \mathrm{MPa}$. The value of equivalent stress is abstracted from respective nodes along the depth direction and the result is shown in Figure. 3(b). There is a compressive layer near the top surface and a tensile layer near the bottom surface, both layers deform plastically. The thickness of the tensile layer and compressive layer is not equal, and the compressive layer is thinner a little. This will lead to the neutral layer close to the top surface. The maximum tensile and the maximum compressive stress are not on the surfaces, but in the interior. This is because the BMG produce plastic deformation 
simultaneously with the strain softening behavior. Figure. 3(b) shows the two strain softening zones.

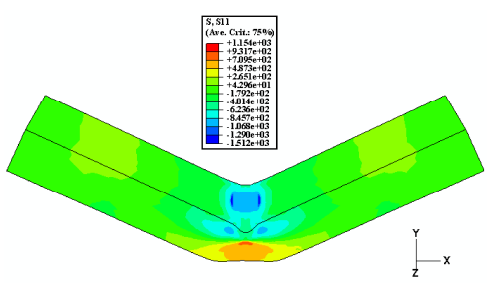

(a)

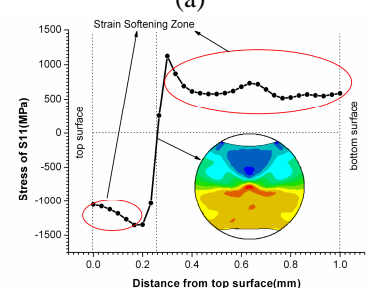

(b)

FIGURE III.

EQUIVALENT STRESS DISTRIBUTION (A) AFTER BENDING (B) IN DEPTH.

Comparing to the beam without laser peening, laser peened beam has a greater compressive stress on the top surface and less tensile stress on the bottom surface shown in Figure. 4. During bending simulation, the bending induced compressive stress is added to laser-induced compressive residual stress, which causes the total compressive stress increase in compressive layer. Relatively, in the tensile layer, the bending induced tensile stress is cancelled out with laser induced compressive residual stress which causes the total tensile stress decrease.

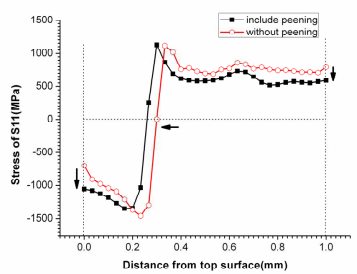

\section{FIGURE IV. COMPARISON OF EQUIVALENT STRESS BETWEEN PEENED AND UN-PEENED BEAM IN DEPTH.}

Figure. 5 shows the distribution of free volume before bending and after bending. The amount of free volume on the top and bottom surfaces near laser spot is obviously greater than that in other region after laser peening. Corresponding to laser peening induced residual stress area, this region which has a high concentration of free volume is most likely to transform into shear band. Figure. 5(b) shows the distribution of free volume after bending. The free volume is mainly concentrated in the tensile layer (corresponding to region 1), the maximum value of free volume is 0.2339 . As the result, the shear band can be clearly observed in tensile layer and expanse to the interior of the beam. Comparing to the tensile layer, the amount of free volume in the compressive layer and in the neutral is relatively small and the value is around 0.15 . The localized shear band plays an important role in plastic deformation and the shear band distribution is mainly dependent on the concentration of free volume and the degree of the deformation. The region 1 located in the tensile layer has a high concentration of free volume which makes it easier to form shear band. The region 2 also has a high value of free volume, while the degree of deformation is far less than that in region 1 , so that the region 1 has hardly no shear band. For region 3 , there is no deformation, so that this region could not form shear band.

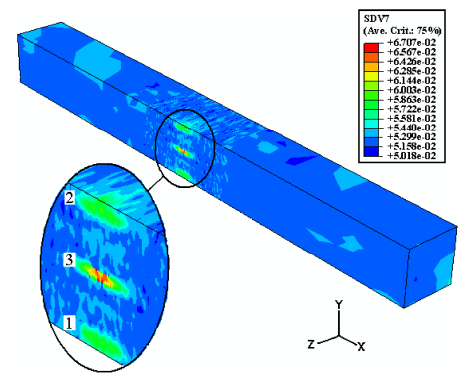

(a)

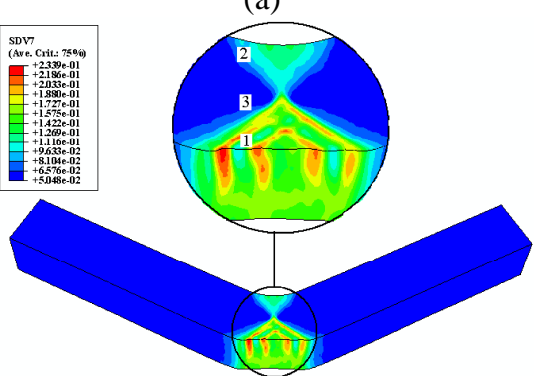

(b)

FIGURE V. FREE VOLUME DISTRIBUTION (A) BEFORE BENDING (B) AFTER BENDING.

In order to further illustrate the plasticity improvement of the laser peened BMG beam, the stress and stain curve has been summarized in Figure. 6. Before bending process, the laser introduced compressive stress is introduced to the surface and the initial effective stress is $328 \mathrm{MPa}$. During bending process, the compressive strain gradually transformed into tensile strain and the value of effective stress increases with the punch moving down, and the material begins to yield accompanied with strain softening behavior. Comparing with un-peened sample, the deformation at yield moment of laser peened BMG is increased and so is the yield strength. This deformation at yield increased from $1.589 \%$ to $3.232 \%$ and the yield strength increased from 1027.76 $\mathrm{MPa}$ to $1097.14 \mathrm{MPa}$, so the strength of the BMG has improved to some extent after the laser peening.

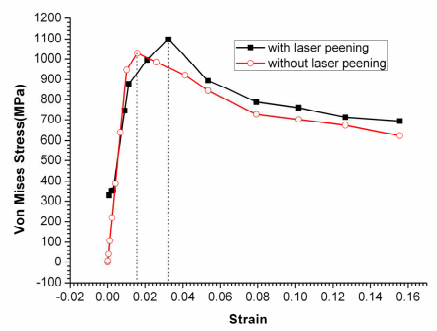

FIGURE VI.

COMPARISON OF THE STRESS-STAIN CURVE OF PEENED AND UN-PEENED BEAM. 


\section{CONCLUSIONS}

In this study, a finite element method is applied to analyze the laser peening process and the subsequent bending process of the $\mathrm{Zr}$-based BMG $\left(\mathrm{Zr}_{41.2} \mathrm{Ti}_{13.8} \mathrm{Cu}_{12.5} \mathrm{Ni}_{10} \mathrm{Be}_{22.5}\right)$ based on a hydrostatic-pressure sensitive and plastically strain ratedependence constitutive model. Meanwhile, the laser pressure pulse model was established. By analyzing the residual stress distribution and the free volume distribution before and after laser peening, the major conclusions can be obtained as follows:

1. After laser peening process, the compressive residual stress is introduced to the top and bottom surface .The tensile residual stress is introduced to the interior. During subsequent bending process, the compressive residual stress on the bottom surface gradually changes into tensile residual stress, and the region of compressive layer is thinner than tensile layer. Both the compressive layer and the tensile layer have strain softening zone. Besides, the bending induced compressive stress is adding up to laser induced compressive residual stress, which causes the total compressive stress increase in the compressive layer. Relatively, in the tensile layer, the bending induced tensile stress is cancelling out with laser induced compressive residual stress, which causes the total tensile stress decrease.

2. After laser peening, the amount of free volume on the top and bottom surface near laser spot is obviously greater than that in other region. During bending process, the tensile layer in the bottom surface has a high concentration of free volume which makes it easier to form shear band.

3. Compared with un-peened sample, the deformation at yield moment of laser peened BMG is increased, and the yield strength is increased too. So the laser peening is good for the improvement of BMG's mechanical performance.

\section{ACKNOWLEDGEMENTS}

This work is supported by the National Natural Science Foundation of China (No. 51205232, 51175301), the Natural Science Foundation of Shandong Province (No. ZR2011EEM016) and Specialized Research Fund for the Doctoral Program of Higher Education (No. 20110131110039).

\section{REFERENCES}

[1] Johnson, William L., Bulk glass-forming metallic alloys: Science and technology, MRS bulletin, pp. 42-56, 1999.

[2] Ashby M. F., Greer A. L., Metallic glasses as structural materials, Scripta Materialia, pp. 321-326, 2006.

[3] Zhang Y, Wang W H, Greer A L., Making metallic glasses plastic by control of residual stress, Nature materials, pp. 857-860, 2006.

[4] Hong Z, Chengye Y., Laser shock processing of 2024-T62 aluminum alloy, Materials Science and Engineering: A, pp. 322-327, 1998.

[5] Montross C S, Wei T, Ye L, et al, Laser shock processing and its effects on microstructure and properties of metal alloys: a review, International Journal of Fatigue, pp.1021-1036, 2002.

[6] Spaepen F., A microscopic mechanism for steady state inhomogeneous flow in metallic glasses, Acta metallurgica, pp. 407-415, 1977.

[7] Turnbull D, Cohen M H., Free-volume model of the amorphous phase: glass transition. The Journal of Chemical Physics, pp. 120-125, 1961.

[8] Gao Y F., An implicit finite element method for simulating inhomogeneous deformation and shear bands of amorphous alloys based on the free-volume model, Modelling and Simulation in Materials Science and Engineering, pp. 1329, 2006.

[9] Wu W F, Zhang C Y, Zhang Y W, et al, Stress gradient enhanced plasticity in a monolithic bulk metallic glass, Intermetallics, pp. 11901198, 2008.

[10] Braisted W, Brockman R., Finite element simulation of laser shock peening, International Journal of Fatigue, pp. 719-724, 1999.

[11] Zhang W, Yao Y L., Micro scale laser shock processing of metallic components, Journal of manufacturing Science and Engineering, pp. 369378, 2002. 